\title{
At the Junction of Genomic and Social Sciences: An Example of Reading Ability and Disability
}

\section{En la Intersección Entre el Genoma y las Ciencias Sociales: Un Ejemplo de la Habilidad e Inhabilidad Lectora}

\author{
Elena L. Grigorenko \\ Yale University and Columbia University, USA \\ Moscow State University, Russia
}

\begin{abstract}
There is more and more traffic at the junction of genomic and social sciences, a complex pattern of intersecting questions, studies, and research possibilities. This busy intersection is likely to become only heavier in the near future. What does this mean for such social sciences as psychology and education? In this essay these issues are explored using the research on the genetic etiology of reading ability and disability as an illustration.
\end{abstract}

Keywords: education, genetic bases, public health, reading ability and disability

\begin{abstract}
Existe un creciente tránsito en la intersección entre el genoma y las ciencias sociales, un patrón complejo de preguntas y estudios que se interceptan, así como múltiples posibilidades de investigación que se abren. Esta sobrecargada intersección es probable que aumente su tráfico en el futuro. ¿Qué significa esto para las ciencias sociales en general y para la psicología y la educación en particular? En este ensayo se exploran estos temas, utilizando como ilustración la investigación sobre la etiología genética de las habilidades de lectura.
\end{abstract}

Palabras clave: educación, bases genéticas, salud pública, habilidad e inhabilidad lectora

\section{What is Known About the Genetic Etiology of Reading Ability and Disability}

However referred to, defined, diagnosed, or measured, reading disability (RD) has always been viewed as a condition whose pathogenesis involves hereditary factors. This idea was initially presented in the description of the first documented case of RD in the late $19^{\text {th }}$ and early $20^{\text {th }}$ century and, although it has been challenged, it has gradually won full (or near-full) acceptance (Fletcher, Lyon, Fuchs, \& Barnes, 2007). Thus, although the assumption that RD is, at least to a certain degree, a genetic disorder has been dominant for a while, the field's understanding of the impact of these heritable factors and the biological and genetic machinery behind them has changed over the century of scientific inquiry into RD.

These changes in understanding have paralleled the emergence of the view that reading is a complex system of cognitive processes that is supported by multiple areas of the brain (Pugh $\&$ McCardle, 2009). Reading engages different cognitive representations that are rooted in various anatomical areas of the brain, each characterized by a particular architecture. In addition,

Elena L. Grigorenko, Child Study Center, Department of Psychology and Department of Epidemiology and Public Health, Yale University, New Haven, CT, USA. Dr. Grigorenko is also affiliated with Columbia University, USA, and Moscow State University, Russia.

The preparation of this article was supported by funds from the USA National Academy of Sciences and National Institutes of Health (DC07665 and HD052120). Grantees undertaking such projects are encouraged to express freely their professional judgment. This article, therefore, does not necessarily represent the position or policies of the National Institutes of Health and no official endorsement should be inferred.

I express my gratitude to Ms. Mei Tan for her editorial assistance and to the anonymous reviewers whose comments resulted in this improved manuscript.

Correspondence concerning this article should be addressed to Elena L. Grigorenko, Child Study Center, Yale University, 230 South Frontage Road, New Haven, CT 06519-1124, USA. E-mail: elena.grigorenko@yale.edu 
the geography of reading in the brain assumes adequate connectivity between various readingrelated areas. In short, the complex multi-process cognitive system of reading is supported by a developmentally emergent amalgamated functional brain system. The current view asserts that this functional brain system is, in turn, established under the influence of and contributed to by a complex constellation of genetic forces. This brain system can be "broken" or challenged in more than one way, causing RD (Pernet, Andersson, Paulesu, \& Demonet, 2009). Likewise, it is plausible to assume that the malfunctioning of the brain system that supports reading may be caused by multiple deficiencies in the corresponding genetic machinery (Grigorenko, 2009). At this point, researchers have only a general sketch of these genetic forces and how they operate. Yet, there are some clear elements of this sketch that seem quite permanent.

It is widely accepted that reading is a skill that requires socialization. In other words, for the overwhelming majority of people the acquisition of reading as a skill requires teaching, that is, the presence of social "others", either people who have already acquired that skill and can transmit the knowledge (e.g., teachers) or social tools that can aid the acquisition of reading by capitalizing on crystallized knowledge of how this skill can be transmitted (e.g., computers). While attempting to understand the genetic machinery behind reading, researchers assume the presence of adequate schooling. In other words, inquiries into the genetic factors underlying reading are conducted under the assumption that deficient reading performance cannot be explained by the absence or the quality of teaching.

Yet, pretty much any characteristic of reading (e.g., reading speed and reading accuracy) or any reading-related process (e.g., phonemic awareness or lexical retrieval), even in the presence of adequate schooling, is continuously distributed in the general population or, in other words, is marked by a wide range of individual differences. Investigations into the sources of these individual differences indicate that a substantial portion of variation between people in both characteristics of reading and reading-related processes can be attributed to the variation in their genetic endowments (i.e., their genomes). Estimates of the magnitude of this portion of variance suggest that, on average, they are somewhere between 40 and $60 \%$ (Grigorenko, 2004), but they vary (a) across the life span, (b) for different languages, and (c) for different social groups. Thus, these estimates are lower if they are obtained earlier in the development of the individual (e.g., among preschoolers or in early grades). These estimates also tend to vary depending on the language in which they are obtained and the specific characteristics of reading they are obtained for, suggesting that there is tremendous variation in how genetic factors manifest themselves in the different languages in which reading is acquired. Finally, these estimates tend to diverge depending on the characteristics of the sample in which they were obtained; these characteristics include socioeconomic status, ethnic constellations, and quality of schooling. These estimates are typically derived from studies of relatives and are called heritability estimates. To obtain heritability estimates researchers recruit different types of genetic relatives, for example, identical (monozygotic) and fraternal (dizygotic) twins or other family members (e.g., parents and offspring, siblings, or members of extended families). Identical twins are assumed to have structurally identical genomes, since they develop from one dividing zygote, whereas fraternal twins are assumed to share only a portion, on average $50 \%$, of their genomes, since they develop from two separate zygotes. Similarly, "averaged" expectations about genetic similarities can be made for any type of relatives. When the degree of genetic relatedness is known, participating relatives can be assessed with reading or related tasks and the degree of their genetic similarity can be compared to the degree of similarity with which they perform these tasks. Multiple statistical techniques have been developed to obtain heritability estimates from different types of relatives. There is no single perfect method for obtaining these estimates; therefore, researchers often use multiple types of relatives and multiple statistical approaches in order to minimize errors and maximize precision. In summary, when characteristics of reading (e.g., speed and accuracy) and performance on reading-related tasks (e.g., tasks of word segmentation and object naming) are considered in the general population, a substantial portion of related individual differences can be attributed to genetic differences between people. Thus, normal variation in reading is associated with genetic variation. 
Genetic influences appear to be of even greater magnitude when challenged (or disabled) reading is considered. In a number of studies, researchers considered heritability estimates in samples selected through poor readers. Limiting variation (often relatives of poor readers demonstrate similarly depressed levels of performance) typically results in higher heritability estimates. Moreover, in these selected samples, researchers used different-in addition to heritability-statistics, such as relative risk estimates. These estimates typically provide an approximation of the likelihood that a relative of a poor reader (i.e., an individual affected with reading disability) will also be a poor reader. These estimates are compared to the general population risk. Specifically, it has been estimated that the prevalence of reading disability is estimated at 5-12\% of school-aged children (Katusic, Colligan, Barbaresi, Schaid, \& Jacobsen, 2001). Relative risk statistics suggest that the prevalence of RD among relatives of individuals who suffer from this disorder is substantially higher than the general population estimates (Schulte-Körne, Deimel, Müller, Gutenbrunner, \& Remschmidt, 1996). These findings also attest to the important role of genes in the development and manifestation of RD. To obtain relative risk statistics researchers recruit families of individuals with RD (so-called RD probands). Multiple types of family units can be utilized in this research: sibling units (i.e., pairs or larger sibships), nuclear families, and extended families. Once again, there is no single method that is ideal; working with different constellations of relatives is associated with various strengths and weaknesses and, similar to heritability studies, to maximize the accuracy and precision of findings researchers utilize multiple approaches.

Although the literature is replete with data supporting the hypothesis that genetic factors are important for understanding individual differences in reading acquisition and reading performance, a clear delineation of the specifics of these factors has been challenging. Currently, the literature contains references to about 20-plus or minus, depending on particular researchers and the utilized phenotypic definition of RD-(Schumacher, Hoffmann, Schmäl, SchulteKörne, \& Nöthen, 2007) potential genetic susceptibility loci (i.e., regions of the genome that have demonstrated a statistically significant linkage to $\mathrm{RD}$; typically these regions involve more than one and often hundreds of genes) and six (Grigorenko \& Naples, 2009) candidate genes for RD (i.e., genes located within susceptibility loci that have been statistically associated with $\mathrm{RD})$, but none of these loci or genes have been either fully accepted or fully rejected by the field. The information that has contributed to the identification of susceptibility loci and candidate genes for RD has been generated by so-called molecular studies of reading and reading-related processes. Unlike heritability and relative risk studies, where participants need to be characterized only behaviorally, that is, through their performance on reading and reading-related tasks, these studies assume the collection of genetic material, DNA, that can be extracted from a variety of biological materials, for example, saliva, hair, skin cells, and blood. These studies can be subdivided into a number of major overlapping categories, by the type of samples they engage (i.e., genetically unrelated cases/probands and matched controls or family units, such as siblings or nuclear and extended families) and by the type of genetic units they target (i.e., specific genes, specific genetic regions, or the whole genome). The first molecular-genetic study of RD was completed with a number of extended families of individuals with RD (Smith, Kimberling, Pennington, \& Lubs, 1983). In such studies, families of individuals with RD (typically, severe $\mathrm{RD})$ are approached and their members are asked to donate both behavior indicators of their performance on reading and reading-related tasks, as well as biological specimens. The task, once again, is to correlate the similarities in performance to similarities in genes, only now, the genetic similarities are not estimated, but measured using special molecular-genetic (i.e., genotyping and sequencing) and statistical (i.e., linkage and association analyses) techniques. Family units can vary from pairs of siblings to large extended families, impacting, correspondingly, the sample size that is needed for enough statistical power to distinguish a true genetic signal from noise. Generally, extended families are harder to identify and harder to work with, but they tend to have more statistical power to identify the genetic source of RD (at least in these families). Smaller familial units, such as nuclear families or sibpairs, are easier to identify and recruit, but the requirements for sample size are much greater. The literature has illustrations 
of different types of samples used in the molecular-genetic studies of RD (Grigorenko, 2005). Similarly, the literature has examples of the utilization of different genetic units as targets. The very first molecular-genetic study of $\mathrm{RD}$ was a whole-genome scan, in which the genome in its entirety was considered in screening for linkage with $\mathrm{RD}$, although that study had very few markers and they were protein markers (the technology then did not allow work with DNA markers). To date, nine genome wide screens for RD have been reported (Brkanac et al., 2008; de Kovel et al., 2004; Fagerheim et al., 1999; Fisher et al., 2002; Igo et al., 2006; Kaminen et al., 2003; Meaburn, Harlaar, Craig, Schalkwyk, \& Plomin, 2008; Nopola-Hemmi et al., 2002; Raskind et al., 2005). These studies utilized hundreds, thousands, and hundreds of thousands of markers, as technology and cost permitted. There are also studies that focus on particular selected regions of the genome. The selection of these regions is typically determined either by a previous whole-genome scan or by a theoretical hypothesis capitalizing on a particular aspect of RD. For example, one early study (Cardon et al., 1994, 1995) focused on the short arm of chromosome 6 (6p), specifically, on the HLA region, assuming that there were connections between RD and left-handedness, and left-handedness and the autoimmune function. Neither of the connections has been confirmed, but the region identified as a result of this study, 6p21, remains a prominent player in the field, harboring two candidate genes for RD, DCDC2 and KIAA0319. Yet, some of the studies settled on candidate regions through different means, such as through a known chromosomal aberration. Denmark, for example, has a health policy of screening all of its newborns for macro-chromosomal changes (e.g., large rearrangements). In these cases, researchers can screen individuals who have such rearrangements for the presence of RD (Buonincontri et al., 2011). The hypothesis, then, is that a gene that is affected by such an aberration is somehow related to RD. As already indicated, at the present time quite a few (more or less 20) different genomic regions are entertained as harboring candidate genes for $\mathrm{RD}$, but this list is likely to continue expanding (Rubenstein, Matsushita, Berninger, Raskind, $\&$ Wijsman, 2011). In addition, as the goal of this work is, ultimately, to identify specific genes whose function is related to the transformation of a brain into a reading brain (i.e., the establishment of brain networks supporting the different types of cognitive representations required for the acquisition of reading), there are studies of specific candidate genes. Currently, there are six candidate genes being evaluated as causal genes for RD (DYX1C1, KIAA0319, DCDC2, ROBO1, MRPL2, and C2orf3), but more genes have been reported as putative additions to this list (Buonincontri et al., 2011; Newbury et al., 2011). At this point, the field contains both support and lack of support for the involvement of each of these genes; thus, the findings are somewhat difficult to interpret, but more time and effort are needed to understand the involvement of each of these genes with reading and its related processes.

\section{How Can These Results Be Interpreted?}

To date, the accumulated findings can be separated into definite and tentative. One definitive conclusion that the field has made is the fact that individual differences in the ways people acquire and practice reading are associated with differences in their genomes. In other words, reading, in its typical and atypical forms, is genetic. The association between reading and the genome appears to be stronger for those individuals who experience difficulties attempting to acquire and exercise reading, compared to those individuals who do it seamlessly (assuming, of course, the proper developmental stage and adequate learning and teaching conditions). This observation is widely accepted in the field and can be perceived as a fact. However, there are caveats. It appears that the strength of the connection between reading and the genome is variable, being weaker in early childhood and, gradually, getting stronger through the school years and into adolescence and adulthood (Byrne et al., 2009). Virtually nothing is known, however, about reading in older adults; there have not been enough studies to investigate the dynamics of heritability estimates for reading and reading-related processes as they continue to develop in old and old-old ages. 
From this ultimate statement (i.e., that reading is, at least partially, controlled by genes), the degree of certainty in interpreting the observations in the field drops off rather quickly. Yes, the heritability estimates are high, but what specific genetic mechanisms generate and substantiate them? The transition from statistical estimates of the role of genetic factors to the identification of these factors has proven to be difficult. This is not specific to studies of reading only; in fact, there is a coined phrase about "missing heritability," referring to the rather common situation of multiple not-so-fruitful attempts to translate the high heritability estimates obtained for a variety of complex human conditions (i.e., disorders such as diabetes, ADHD, and autism) into their underlying genetic foundations (Avramopoulos, 2010). The field of understanding the genetic bases of reading has the imprint of the field of the genetics and genomics of complex disorders in general. Specifically, many initial positive findings are often followed by non-replications, suggesting either a high level of heterogeneity of the involved genetic mechanisms or a high level of false positive results. Either interpretation is difficult to grapple with. The former logically leads to a supposition of the field's inability to generalize effectively from specific deficiencies that might be characteristic of specific families, or from specific samples to the general population. The latter assumes that the initial samples were too small and lacking statistical power to differentiate true and false findings, and that much larger samples are needed to weed out the initial field of promising results by marking a number of them as false positives.

Needless to say, neither of these perspectives appeals. Yet, although these two possibilities are the most obvious ones, they are not the only alternatives. The first possibility pertains to the fact that the last few years of studies in genetics and genomics have resulted in breath-taking discoveries that overshoot all of the expectations raised by the first generation of the human genome sequence in 2000. Among these discoveries, three, arguably, deserve the most attention: (a) other, in addition to previously known, sources of structural variation in the genome; (b) the role of epigenetic mechanisms in understanding how the genome changes throughout development and in different contexts and experiences (e.g., experiences ranging from diet to schooling); and (c) the role of unstable or movable elements in the genome. Although it is not possible to discuss in detail these "new" genetic mechanisms in this overview, it is important to note that none of them have been considered in studies of the genetic bases of reading and RD. Clearly, there is much to do there. The second possibility is related to the attempt of the field to sift through the findings and, putting aside their inconsistent nature, try to hypothesize about various underlying theoretical considerations that might bring these findings together. Thus, although, at first glance, the collection of the six candidate genes for RD seems quite disparate, they all appear to be contributing, in different degrees, to the process of brain maturation and neuronal migration (Galaburda, LoTurco, Ramus, Fitch, \& Rosen, 2006). Thus, through further investigations it is possible that the emergent system will lead the field toward the involvement of particular genetic pathways, rather than specific genes.

\section{Why Might These Findings Be of Interest to Psychologists and Educators?}

Recent rapid progress in cellular and molecular technologies and the speedy application of these technologies in research have generated a lot of hype in the scientific community and numerous subsequent remarkable discoveries. These discoveries are fuelling hopes and expectations regarding radical changes in the ways that prevention, treatment, and remediation-recovery are carried out in the fields of medical conditions and neuropsychiatric disorders. Some of these discoveries have already generated practical applications, mostly in the areas of diagnostic and pharmaceutical medicine. A new field called public health genomics (PHG) has emerged, a rapidly developing multidisciplinary research and practice area whose objective is to bring, responsibly and effectively, genome-based knowledge into public health with the goal of improving population health (Brand, Schroder, Brand, \& Zimmern, 2006; Brand, 2007; Burke, Khoury, Stewart, Zimmern, \& Bellagio Group, 2006). PHG is closely related to personalized genomic medicine, a subfield of medicine where genetic information is used to improve 
health outcomes (Guttmacher \& Collins, 2002; Holtzman, 2006; Khoury \& Gwinn, 2006) via incorporating data on an individual's genotype, family medical history, and/or expression analysis into disease risk assessment (Khoury, 2003). This genome-based knowledge is referred to as the "-omics"- a family of sciences focusing on the structure and function of the genome: the examination of the genome (genomics), the messenger RNA transcribed from active genes (transcriptomics), the proteins coded for by this mRNA (proteomics) and the metabolites which are the end products of gene expression (metabolomics) — of today (Tan, Lim, Khan, \& Ranganathan, 2009) and is characterized by an overabundance of data and information, along with the enormous opportunities associated with the utilization of these data.

However, it is probably accurate to say that the hype is still mostly limited to the scientific community. Practitioners rarely use, still, these discoveries in their everyday operations and, moreover, often lack understanding of the current discoveries and developments in the field (Chen \& Goodson, 2007). Similarly, interactions with the general public reveal the lack of depth in understanding the general scope of recent discoveries in genetics and genomics, prevalent misconceptions reflective of a deficiency of knowledge (Chapple, May, \& Campion, 1995; Condit, 2001; Richards \& Ponder, 1996; Walter, Emery, Braithwaite, \& Marteau, 2004), negative biases toward particular terms (e.g., mutation; Condit, Dubriwny, Lynch, \& Parrott, 2004), and the presence of strong personal, moral, and global concerns (Barns, Schibeci, Davison, \& Shaw, 2000; Bates, Lynch, Bevan, \& Condit, 2005; Henneman, Timmermans, \& van der Wal, 2004) about the use and abuse of genetic and genomic information (Hahn et al., 2010). Yet, the very success of the integration of genome-based knowledge into public health relies on the public's ability to understand the need to collect and apply family history that is relevant to diseases and disorders and the importance of being able to consult with knowledgeable healthcare providers and to self-trigger and self-monitor health-related behaviors (Charles, Gafni, \& Whelan, 1999; Sheridan, Harris, \& Woolf, 2004).

It is fair to say that very little (if any) of these discoveries, at least at this point, have made their impact on either behavioral therapy or education. Although there are no data that have been collected specifically with or from educators or other types of providers in the sphere of education (e.g., educational tutors or occupational and behavior therapists), there is no reason to believe that their level of mastery of this knowledge is any different from that of the general public. Yet, although perhaps seemingly a bit more distant from recent genome-based discoveries, educators are only a step away from healthcare practitioners. Indeed, developmental disorders, especially common developmental disorders such as learning disabilities (LDs) in general and RD in particular, are public health issues that are serviced, primarily, by educators.

If, indeed, RD is recognized as a public health condition, then current thinking with regard to PHG, as with other common conditions, can be applied to understanding the role of genetics and genomics in issues pertaining to RD. In this context, a number of other useful parallels can be drawn connecting the literature on PHG and RD.

The essence of PHG is to personalize health care to maximize the well-being and longevity of each individual. The essence of quality education is the individualization of teaching and learning to maximize productive accomplishment and life satisfaction. Both personalized medicine and individualized education show similar trends in their utilization of technology and multimedia, engaging multiple sources of information and knowledge, and capitalizing on the usage of profiles of information rather than single data points on an individual. Both personalized medicine and education demonstrate changes in their definition of "problems." In medicine, previously, disease was defined through the presence of symptoms. Now, having accumulated a substantial corpus of data on the genomic bases of many diseases, medicine defines diseases through the presence of a genotype or a genomic signature that confers a susceptibility to these clinical symptoms (Ford et al., 2008). Similarly, education is striving to find early precursors of various learning difficulties and focusing on prevention rather than on failure and subsequent remediation. Yet, although PHG has focused on the utilization of genomic information in medicine and public health since early in this century, education has largely ignored the advances in genome-based knowledge. Yet, similar to the situation concerning com- 
mon diseases in medicine, educational difficulties appear to have genetic bases. In fact, heritability estimates for academic difficulties exceed those for such common medical conditions as obesity, diabetes, and cardio-vascular problems. So, if healthcare practitioners are applying genome-based knowledge to the understanding, prevention, and treatment of such common conditions in medicine, then why should not educators apply this knowledge to dealing with common LD, such as RD? In fact, the "preventive" logic of PHG seems totally reasonable when applied to common LD. If genetic bases of LD are understood and there are tools and resources available for diagnostic purposes, educators might no longer have to wait for signs of academic failure. If indicators of genetic risks are identified, the specific measure aimed at preventing the onset of difficulty or failure, or at least minimizing their extent, will become increasingly powerful. And, although the initial costs of early diagnostic and preventive actions might not be negligible, subsequent remedial costs might be substantially diminished by these activities. Although this type of reasoning has not been practiced in education on a large scale, it has been present in the public health literature for over a decade (e.g., Gibson, Martin, \& Singer, 2002; Zajtchuk, 1999), and there is much to learn from this literature.

One such useful line of discourse addresses the ways and stages of translating genetic and genomic discoveries into public health applications. Although many translation paradigms have been proposed, only one is exemplified here, developed by Khoury and colleagues (Agurs-Collins et al., 2008; Khoury et al., 2009; Khoury, Gwinn, et al., 2007; Khoury, Valdez, \& Albright, 2008). Connecting -omics sciences with public health, four different stages are differentiated for the purposes of validating scientific knowledge and integrating it into disease control and prevention programs (Khoury et al., 2009).

At the first stage, the discovery stage, also referred to as the analytical validity stage, research attempts to connect a genetic or genomic mechanism with a particular public health condition. At the second stage, referred to as the clinical validity phase, research appraises the value of the connection established in the first stage for health practice, validating the firststage observations in different settings and different samples to develop evidence and assess its replicability and robustness. At this stage, evidence-based guidelines connecting a genetic or genomic discovery and a public health issue are developed. Subsequently, at the third stage, referred to as the clinical utility phase, research attempts to apply these stage-two guidelines into health practice by mechanisms of knowledge transfer and delivery, as well as dissemination and diffusion practices. Only having planted these practices into every-day application on a large scale can research, at stage four, access health outcomes of a genomic discovery in practice. This stage engages multiple ethical and social considerations.

It is important to note that the literature today acknowledges that most current genomebased research is unfolding within stage one (Khoury et al., 2008). It has been estimated that only approximately $3 \%$ of published studies are conducted within stage two and only a very few, at stage three or four-studies of pre- and perinatal genetic and genomic testing for rare disorders-(Khoury, Gwinn, et al., 2007).

In the context of viewing $\mathrm{LD}$ (and, correspondingly, RD) as a public-health problem and capitalizing on the Khoury and colleagues translational paradigm, what is the current state of affairs with respect to the relevant genetics and genomic discoveries in the field of LD in general and RD in particular?

Currently, the majority of activity is still happening at stage one. This stage defines the analytical validity (Haddow \& Palomaki, 2003) of whatever genetic or genomic test needs to be conducted so that the genotype of interest for the disorder (in this case, RD) may be measured accurately, reliably, and at a minimum expense. Although a number of specific candidate genes for $\mathrm{RD}$ have been identified, the field is rather far from grasping the mechanism that unifies these genes in their RD-specific action. Moreover, the field is also rather far from verifying the numerous hypotheses regarding the specific genomic regions and other candidate genes that are currently under consideration. In other words, stage one of the related work in the field of $\mathrm{RD}$ is far from being completed. It is rapidly unfolding, but it is too early, at this stage, to ascertain the specific genetic tests that have diagnostic validity for RD. 
Yet, the research on some of the candidate genes (e.g., KIAA0319, DCDC2, ROBO1, and $D Y X 1 C 1)$ has transitioned to stage two, where the degree of association between these genes and $\mathrm{RD}$ is being validated in a variety of samples and contexts, but the field has yet to formalize the various stage-two findings into comprehensive guidelines connecting the specific genetic variants in these genes or the specific mechanisms these genes support to genetic vulnerability for $\mathrm{RD}$ or its specific components ${ }^{1}$. These activities are crucially important for the clinical validity (Haddow \& Palomaki, 2003) of a genetic or genomic finding, that is, its capacity to detect or predict the condition of interest (e.g., RD). Moreover, establishing and explicating these connections is absolutely necessary for the possibility of transitioning to stage-three practices that should involve service providers for individuals with $\mathrm{RD}$, ranging from educators to medical doctors and career counselors. These guidelines need to be as clear and as robust as possible, presenting a list of vulnerability genetic mechanisms and identifying risks associated with these mechanisms. As it appears now, it is quite likely, based on the indications from the RD literature so far (Bates et al., 2011; Meaburn et al., 2008; Newbury et al., 2011; Paracchini et al., 2008) and the evidence from other common disorders ${ }^{2}$ (Khoury, Little, et al., 2007), that the relative risks associated with each of these vulnerability genetic mechanisms is of small magnitude. Thus, the field should expect either a long list of genetic risk variants for $\mathrm{RD}$ or a discovery of some type of clustering for these variants that result in a substantial magnification of risk, when more than one variant is present in an individual. Once again, though, the evidence in the field of RD that has been accumulated so far is rather distant from being leveraged into policy recommendations. This, of course, assumes that all policy should be evidence-based and, in many cases, especially in education research, this is simply not the case. Yet, the field is working very hard both at stage one-generating new discoveries on the genetic bases of RD-and at stage two, testing the extent of the generalizability of these discoveries and their role in various samples and contexts. A fundamental question that needs to be answered at stage two is whether an understanding of the genetic mechanism for RD may be used for pharmacological treatment of this and related disabilities (i.e., so that pharmacological, but not educational, approaches can be individualized), for individualized education (i.e., so that educational approaches are matched to genetic mechanisms and pharmacological treatment is engaged minimally or not at all), or for both. There have been attempts to treat RD pharmacologically in Europe, but not in the United States. Whether the idea of treating RD pharmacologically will be even acceptable in the United States is not a trivial question.

At stage three, a cadre of qualified and knowledgeable providers should be able to implement the guidelines developed at stage two in their everyday practice. This phase of clinical utility is aimed at establishing the net health benefit resulting from the introduction of a particular diagnostic procedure related to the genetic or genomic findings and associated with relevant interventions (Haddow \& Palomaki, 2003). This stage ideally requires well designed studies in the community. As the ultimate goal of PHG is to generate public health policies and recommendations that can be easily translated in individualized approaches for the beneficiaries of these policies, and since the major "battle" that engages individuals with RD unfolds in schooling, if there are ever PHG policies for RD, they will inevitably involve schools. At this point, it is unclear whether these policies will be delivered by educators themselves or by PHG providers placed in schools (similar to the medical outreach services delivered to schools through school nurses), but it is clear that academic activities will be a part of the PHG policies that address RD.

\footnotetext{
1 To appreciate the magnitude of the task faced by researchers of the genetic bases of RD, it is important to consider comparable efforts with regard to other complex common disorders. The Centers for Disease Control and Prevention has developed two knowledge synthesis initiatives in genomics (for detail, see Khoury et al., 2008; Yu, Gwinn, Clyne, Yesupriya, \& Khoury, 2008): The Human Genome Epidemiology Network (HuGENet), (http://www.cdc.gov/genomics/hugenet/default.htm) and The Evaluation of Genomic Applications in Practice and Prevention (EGAPP) initiative (http://www.egappreviews.org). The first initiative is aimed at developing the knowledge base on genes and diseases. The second initiative is intended to comment on the clinical validity and utility of genetic tests in specific clinical and population health scenarios.

2 As determined by genetic association studies, the estimated relative risk for common diseases is around 1.5 (Khoury, Little, Gwinn, \& Ioannidis, 2007).
} 
Finally, only when there are data collected at stage three with regard to short- and longterm outcomes of RD-related PHG will the field be able to qualify and quantify the importance and relevance of the findings described here (and the findings to be made) to RD-related outcomes. Research at this stage calls for joint efforts from public health providers, bench and education scientists, economists, policy-makers, stakeholders and the community. There is a tremendous body of literature indicating that reading failure and deficiencies in the mastery of reading are risk factors for many negative life outcomes. Correspondingly, an assessment of the impact of RD-related PHG needs to be coupled not only with short-term academic outcomes, but with long-term life outcomes.

It is likely that the "movement" through Khoury's stages in the field of LD is not going to be easy. Even if the first-stage findings are convincingly validated at the second stage, and the variability of findings we see now is interpreted in a systematic and interpretable manner such that the mechanism behind these findings is understood, the field faces the behemoth tasks of completing stages three and four before being able to arrive to a conclusion with regard to the ultimate value of genetic and genomic studies for the prevention and treatment of RD and its associated deficits, and for the enhancement and promotion of literacy. Yet, many current public health policies are associated with breakthroughs and shortcuts; it has certainly been the case for many PHG applications and might well be the case for its RD-related applications. Thus, while the field is making its way through Khoury's stages, whether in a sequential or simultaneous manner, it is important to focus on tasks that connect ongoing genetic and genomic $\mathrm{RD}$-associated research, at whatever stage, with the public's perception of it. There are at least three such tasks that appear to be of high priority.

The first task is that of educating the public. If traditional PHG for conventional health conditions, such as cancer and diabetes, generate so much misunderstanding and misinterpretation by the general public, the task of communicating the idea of PHG for developmental disorders, especially such common disorders as LD, will be even more difficult. Yet, it has to be done because modern public health policies count on and are targeted at an educated consumer. The literature indicates that genome-based knowledge is associated with misconceptions and misinterpretations in the public as a whole (Burton \& Adams, 2009), but appears to be particularly the case for various minority groups (Hahn et al., 2010). One of the major issues here is the removal of the negative connotation associated with the concepts of the genomebased science and $\mathrm{PHG}^{3}$.

The second task, even more mammoth, is educating the providers, the professionals of both fields of medicine and education, who serve individuals with LD. Here of note is a tremendous discrepancy in the literature, where there is a large current body of work on the importance of including the basics of knowledge of genome-based sciences in the education of medical practitioners and virtually no work advocating the importance of the mastery of these basics by educators.

The third and, perhaps, the most important task is to trigger and stimulate substantial discourse on the intersection of PHG and education. There is a large-scale highly engaging discussion in the literature on the development of national policies on PHG in the United States and elsewhere (González-Andrade \& López-Pulles, 2010; Little et al., 2009; Metcalfe, Bittles, O'Leary, \& Emery, 2009), but the issues concerning where and how PHG and education should meet are not part of this discussion. Because PHG is aimed primarily at common conditions directly associated with lifestyle (Agurs-Collins et al., 2008; Boccia, Brand, Brand, \& Ricciardi, 2009; Khoury et al., 2008; Sanderson, Wardle, \& Humphries, 2008), it seems that such life-long conditions as RD, which are directly associated with life outcomes, should be a part of these discussions.

Completing these three tasks is crucial for the development, implementation, and evaluation of PHG for LD. Thus, engaging with them early (now?) is highly important. The observed slow rate of translation of genome-based knowledge into public health (Boccia et al., 2009) has

3 For example, it has been reported that the word variant is preferred by the general public over the word mutation. 
been connected with numerous factors, such as the low relative risk for common disorders, the complexity of the four-stage translational process, and the lack of critical knowledge in the public. An unfortunate mark of the rapid development of genome-based sciences and technologies has been a popularization - to the point of hyperbole - of the scale and immediacy of the application of these developments to health-related practices (Davey Smith et al., 2005; Kamerow, 2008). Such harmful popularization, coupled with commercial potential, has often resulted in ill-justified use of genetic and genomic testing for susceptibility to complex disorders, mostly with no clear application or guidance for proper utilization of this knowledge. It is inevitable, as any knowledge-based progress, that soon, perhaps even in the foreseeable future, the genome will become part of the common record for personalized medicine and individualized education. Thus, it is very important to prepare the general public and service providers for this transformation of the genome from something that once cost a tremendous amount of funds to sequence, in draft, only ten years ago, but soon will become just a part of the birth record for each of us.

\section{References}

Agurs-Collins, T., Khoury, M. J., Simon-Morton, D., Olster, D. H., Harris, J. R., \& Milner, J. A. (2008). Public health genomics: Translating obesity genomics research into population health benefits. Obesity, 16, Supplement 3s, S85-S94. doi:10.1038/oby.2008.517

Avramopoulos, D. (2010). Genetics of psychiatric disorders methods: Molecular approaches. Psychiatric Clinics of North America, 33, 1-13. doi:10.1016/j.psc.2009.12.006

Barns, I., Schibeci, R., Davison, A., \& Shaw, R. (2000). "What do you think about genetic medicine?" Facilitating sociable public discourse on developments in the new genetics. Science, Technology, \& Human Values, 25, 283308. doi:10.1177/016224390002500302

Bates, B. R., Lynch, J. A., Bevan, J. L., \& Condit, C. M. (2005). Warranted concerns, warranted outlooks: A focus group study of public understandings of genetic research. Social Science \& Medicine, 60, 331-344. doi:10.1016/ j.socscimed.2004.05.012

Bates, T. C., Luciano, M., Medland, S. E., Montgomery, G. W., Wright, M. J., \& Martin, N. G. (2011). Genetic variance in a component of the language acquisition device: ROBO1 polymorphisms associated with phonological buffer deficits. Behavior Genetics, 41, 50-57. doi:10.1007/s10519-010-9402-9

Boccia, S., Brand, A., Brand, H., \& Ricciardi, G. (2009). The integration of genome-based information for common diseases into health policy and healthcare as a major challenge for public health genomics: The example of the me thylenetetrahydrofolate reductase gene in non-cancer diseases. Mutation Research-Fundamental and Molecular Mechanisms of Mutagenesis, 667, 27-34. doi:10.1016/j.mrfmmm. 2008.10.003

Brand, A., Schröder, P., Brand, H., \& Zimmern, R. (2006). Getting ready for the future: Integration of genomics into public health research, policy and practice in Europe and globally. Community Genetics, 9, 67-71. doi:10.1159/000090696

Brand, H. (2007). Good governance for the public's health [Editorial]. European Journal of Public Health, $17,541$. doi:10.1093/eurpub/ckm104

Brkanac, Z., Chapman, N. H., Igo, R. P., Matsushita, M. M., Nielsen, K., Berninger, V. W. ... Raskind, W. H. (2008). Genome scan of a nonword repetition phenotype in families with dyslexia: Evidence for multiple loci. Behavior Genetics, 38, 462-475. doi:10.1007/s10519-008-9215-2

Buonincontri, R., Bache, I., Silahtaroglu, A., Elbro, C., Veber Nielsen, A.-M., Ullmann, R. ... Tommerup, N. (2011). A cohort of balanced reciprocal translocations associated with dyslexia: Identification of two putative candidate genes at DYX1. Behavior Genetics, 41, 125-133. doi:10.1007/s10519-010-9389-2

Burke, W., Khoury, M. J., Stewart, A., Zimmern, R. L., \& Bellagio Group. (2006). The path from genome-based research to population health: Development of an international public health genomics network. Genetics in Medicine, 8, 451-458. doi:10.1097/01.gim.0000228213.72256.8c

Burton, H. \& Adams, M. (2009). Professional education and training in public health genomics: A working policy developed on behalf of the Public Health Genomics European Network. Public Health Genomics, 12, $216-224$. doi:10.1159/000200019

Byrne, B., Coventry, W. L., Olson, R. K., Samuelsson, S., Corley, R., Willcutt, E. G. ... Defries, J. C. (2009). Genetic and environmental influences on aspects of literacy and language in early childhood: Continuity and change from preschool to grade 2. Journal of Neurolinguistics, 22, 219-236. doi:10.1016/j.jneuroling.2008.09.003

Cardon, L. R., Smith, S. D., Fulker, D. W., Kimberling, W. J., Pennington, B. F., \& DeFries, J. C. (1994). Quantitative trait locus for reading disability on chromosome 6. Science, 226, 276-279. doi:10.1126/science.7939663

Cardon, L. R., Smith, S. D., Fulker, D. W., Kimberling, W. J., Pennington, B. F., \& DeFries, J. C. (1995). Quantitative trait locus for reading disability: Correction. Science, 268, 1553. doi:10.1126/science.7777847

Chapple, A., May, C., \& Campion, P. (1995). Lay understanding of genetic disease: A British study of families attending a genetic counseling service. Journal of Genetic Counseling, 4, 281-300. doi:10.1007/BF01408074

Charles, C., Gafni, A., \& Whelan, T. (1999). Decision-making in the physician-patient encounter: Revisiting the shared treatment decision-making model. Social Science \& Medicine, 49, 651-661. doi:10.1016/S0277-9536(99)00145-8 
Chen, L-S. \& Goodson, P. (2007). Public health genomics knowledge and attitudes: A survey of public health educators in the United States. Genetics in Medicine, 9, 496-503. doi:10.1097/GIM.0b013e31812e95b5

Condit, C. (2001). What is 'public opinion' about genetics? Nature Reviews Genetics, 2, 811-815. doi:10.1038/35093580

Condit, C. M., Dubriwny, T., Lynch, J., \& Parrott, R. (2004). Lay people's understanding of and preference against the word "mutation". American Journal of Medical Genetics Part A, 130A, 245-250. doi:10.1002/ajmg.a.30264

Davey Smith, G., Ebrahim, S., Lewis, S., Hansell, A. L., Palmer, L. J., \& Burton, P. R. (2005). Genetic epidemiology and public health: Hope, hype, and future prospects. The Lancet, 366, 1484-1498. doi:10.1016/S0140-6736(05)67601-5

de Kovel, C. G. F., Hol, F. A., Heister, J. G. A. M., Willemen, J. J. H. T., Sandkuijl, L. A., Franke, B., \& Padberg, G. W. (2004). Genomewide scan identifies susceptibility locus for dyslexia on Xq27 in an extended Dutch family. Journal of Medical Genetics, 41, 652-657. doi:10.1136/jmg.2003.012294

Fagerheim, T., Raeymaekers, P., Tonnessen, F. E., Pedersen, M., Tranebjaerg, L., \& Lubs, H. A. (1999). A new gene (DYX3) for dyslexia is located on chromosome 2. Journal of Medical Genetics, 36, 664-669. doi:10.1136/ jmg.36.9.664

Fisher, S. E., Francks, C., Marlow, A. J., MacPhie, I. L., Newbury, D. F., Cardon, L. R. ... Monaco, A. P..(2002). Independent genome-wide scans identify a chromosome 18 quantitative-trait locus influencing dyslexia. Nature Genetics, 30, 86-91. doi:10.1038/ng792

Fletcher, J. M., Lyon, G. R., Fuchs, L. S., \& Barnes, M. A. (2007). Learning disabilities: From identification to intervention. New York, NY: Guilford.

Ford, P., Seymour, G., Beeley, J. A., Curro, F., DePaola, D., Ferguson, D. ... Claffey, N. (2008). Adapting to changes in molecular biosciences and technologies. European Journal of Dental Education, 12(Supplement s1), 40-47. doi:10.1111/j.1600-0579.2007.00479.x

Galaburda, A. M., LoTurco, J., Ramus, F., Fitch, R. H., \& Rosen, G. D. (2006). From genes to behavior in developmental dyslexia. Nature Neuroscience, 9, 1213-1217. doi:10.1038/nn1772

Gibson, J. L., Martin, D. K., \& Singer, P. A. (2002). Priority setting for new technologies in medicine: A transdisciplinary study. BMC Health Services Research, 2, Article 14. doi:10.1186/1472-6963-2-14

González-Andrade, F. \& López-Pulles, R. (2010). Ecuador: Public health genomics. Public Health Genomics, 13, 171180. doi:10.1159/000249817

Grigorenko, E. L. (2004). Genetic bases of developmental dyslexia: A capsule review of heritability estimates. Enfance, 3, 273-287. doi:10.3917/enf.563.0273

Grigorenko, E. L. (2005). A conservative meta-analysis of linkage and linkage-association studies of developmental dyslexia. Scientific Studies of Reading, 9, 285-316. doi:10.1207/s1532799xssr0903_6

Grigorenko, E. L. (2009). At the height of fashion: What genetics can teach us about neurodevelopmental disabilities. Current Opinion in Neurology, 22, 126-130. doi:10.1097/WCO.0b013e3283292414

Grigorenko, E. L. \& Naples, A. J. (2009). The devil is in the details: Decoding the genetics of reading. In K. Pugh \& P. McCardle (Eds.), How children learn to read: Current issues and new directions in the integration of cognition, neurobiology and genetics of reading and dyslexia research and practice (pp. 133-148). New York, NY: Psychological Press.

Guttmacher, A. E. \& Collins, F. S. (2002). Genomic medicine-A primer. The New England Journal of Medicine, 347, 1512-1520.

Haddow, J. E. \& Palomaki, G. E. (2003). ACCE: A model process for evaluating data on emerging genetic tests. In M. J. Khoury, J. Little, \& W. Burke (Eds.), Human genome epidemiology: A scientific foundation for using genetic information to improve health and prevent disease (pp. 217-233). New York, NY: Oxford University Press.

Hahn, S., Letvak, S., Powell, K., Christianson, C., Wallace, D., Speer, M. ... Henrich, V. V. (2010). A community's awareness and perceptions of genomic medicine. Public Health Genomics, 13, 63-71. doi:10.1159/000218712

Henneman, L., Timmermans, D. R. M., \& van der Wal, G. (2004). Public experiences, knowledge and expectations about medical genetics and the use of genetic information. Community Genetics, 7, 33-43. doi:10.1159/000080302

Holtzman, N. A. (2006). What role for public health in genetics and vice versa? Community Genetics, 9, 8-20. doi:10.1159/000090688

Igo Jr., R. P., Chapman, N. H., Berninger, V. W., Matsushita, M., Brkanac, Z., Rothstein, J. H. ... Wijsman, E. M. (2006). Genomewide scan for real-word reading subphenotypes of dyslexia: Novel chromosome 13 locus and genetic complexity. American Journal of Medical Genetics Part B: Neuropsychiatric Genetics, 141B, 15-27. doi:10.1002/ ajmg.b.30245

Kamerow, D. (2008). Yankee doodling: Waiting for the genetic revolution. BMJ, 336, Observation 22. doi:10.1136/ bmj.39437.453102.0F

Kaminen, N., Hannula-Jouppi, K., Kestilä, M., Lahermo, P., Muller, K., Kaaranen, M. ... Kere, J. (2003). A genome scan for developmental dyslexia confirms linkage to chromosome 2 p11 and suggests a new locus on $7 \mathrm{q} 32$. Journal of Medical Genetics, 40, 340-345. doi:10.1136/jmg.40.5.340

Katusic, S. K., Colligan, R. C., Barbaresi, W. J., Schaid, D. J., \& Jacobsen, S. J. (2001). Incidence of reading disability in a population-based birth cohort, 1976-1982, Rochester, Minn. Mayo Clinic Proceedings, 76, 1081-1092. doi:10.4065/76.11.1081

Khoury, M. J. (2003). Genetics and genomics in practice: The continuum from genetic disease to genetic information in health and disease. Genetics in Medicine, 5, 261-268. doi:10.1097/01.GIM.0000076977.90682.A5

Khoury, M. J., Bowen, S., Bradley, L. A., Coates, R., Dowling, N. F., Gwinn, M. ... Yoon, P. W. (2009). A decade of public health genomics in the United States: Centers for disease control and prevention 1997-2007. Public Health Genomics, 12, 20-29. doi:10.1159/000153427

Khoury, M. J. \& Gwinn, M. (2006). What role for public health in genetics and vice versa? [Letter to the Editor]. Community Genetics, 9, 282. doi:10.1159/000094481 
Khoury, M. J., Gwinn, M., Yoon, P. W., Dowling, N., Moore, C. A., \& Bradley, L. (2007). The continuum of translation research in genomic medicine: How can we accelerate the appropriate integration of human genome discoveries into health care and disease prevention? Genetics in Medicine, 9, 665-674. doi:10.1097/GIM.0b013e31815699d0

Khoury, M. J., Little, J., Gwinn, M., \& Ioannidis, J. P. A. (2007). On the synthesis and interpretation of consistent but weak gene-disease associations in the era of genome-wide association studies. International Journal of Epidemiology, 36, 439-445. doi:10.1093/ije/dyl253

Khoury, M. J., Valdez, R., \& Albright, A. (2008). Public health genomics approach to type 2 diabetes. Diabetes, 57, 2911-2914. doi:10.2337/db08-1045

Little, J., Potter, B., Allanson, J., Caulfield, T., Carroll, J. C., \& Wilson, B. (2009). Canada: Public health genomics. Public Health Genomics, 12, 112-120. doi:10.1159/000156113

Meaburn, E. L., Harlaar, N., Craig, I. W., Schalkwyk, L. C., \& Plomin, R. (2008). Quantitative trait locus association scan of early reading disability and ability using pooled DNA and 100K SNP microarrays in a sample of 5760 children. Molecular Psychiatry, 13, 729-740. doi:10.1038/sj.mp.4002063

Metcalfe, S. A., Bittles, A. H., O’Leary, P., \& Emery, J. (2009). Australia: Public health genomics. Public Health Genomics, 12, 121-128. doi:10.1159/000160666

Newbury, D. F., Paracchini, S., Scerri, T. S., Winchester, L., Addis, L., Richardson, A. J. ... Monaco, A. P. (2011). Investigation of dyslexia and SLI risk variants in reading- and language-impaired subjects. Behavior Genetics, 41, 90-104. doi:10.1007/s10519-010-9424-3

Nopola-Hemmi, J., Myllyluoma, B., Voutilainen, A., Leinonen, S., Kere, J., \& Ahonen, T. (2002). Familial dyslexia: Neurocognitive and genetic correlation in a large Finnish family. Developmental Medicine \& Child Neurology, 44, 580-586. doi:10.1111/j.1469-8749.2002.tb00842.x

Paracchini, S., Steer, C. D., Buckingham, L.-L., Morris, A. P., Ring, S., Scerri, T. ... Monaco, A. P. (2008). Association of the KIAA0319 dyslexia susceptibility gene with reading skills in the general population. The American Journal of Psychiatry, 165, 1576-1584. doi:10.1176/appi.ajp.2008.07121872

Pernet, C. R., Andersson, J., Paulesu, E., \& Demonet, J. F. (2009). When all hypotheses are right: A multifocal account of dyslexia. Human Brain Mapping, 30, 2278-2292. doi:10.1002/hbm.20670

Pugh, K., \& McCardle, P. (Eds.). (2009). How children learn to read: Current issues and new directions in the integration of cognition, neurobiology and genetics of reading and dyslexia research and practice. New York, NY: Psychology Press.

Raskind, W. H., Igo Jr., R. P., Chapman, N. H., Berninger, V. W., Thomson, J. B., Matsushita, M. ... Wijsman, E. M. (2005). A genome scan in multigenerational families with dyslexia: Identification of a novel locus on chromosome $2 \mathrm{q}$ that contributes to phonological decoding efficiency. Molecular Psychiatry, 10, 699-711. doi:10.1038/sj.mp.4001657

Richards, M. \& Ponder, M. (1996). Lay understanding of genetics: A test of a hypothesis. Journal of Medical Genetics, 33, 1032-1036. doi:10.1136/jmg.33.12.1032

Rubenstein, K., Matsushita, M., Berninger, V. W., Raskind, W. H., \& Wijsman, E. M. (2011). Genome scan for spelling deficits: Effects of verbal IQ on models of transmission and trait gene localization. Behavior Genetics, 41, 31-42. doi:10.1007/s10519-010-9390-9

Sanderson, S. C., Wardle, J., \& Humphries, S. E. (2008). Public health genomics and genetic test evaluation: The challenge of conducting behavioural research on the utility of lifestyle-genetic tests. Journal of Nutrigenetics \& Nutrigenomics, 1, 224-231. doi:10.1159/000149826

Schulte-Körne, G., Deimel, W., Müller, K., Gutenbrunner, C., \& Remschmidt, H. (1996). Familial aggregation of spelling disability. Journal of Child Psychology and Psychiatry, 37, 817-822. doi:10.1111/j.1469-7610.1996.tb01477.x

Schumacher, J., Hoffmann, P., Schmäl, C., Schulte-Körne, G., \& Nöthen, M. M. (2007). Genetics of dyslexia: The evolving landscape. Journal of Medical Genetics, 44, 289-297. doi:10.1136/jmg.2006.046516

Sheridan, S. L., Harris, R. P., \& Woolf, S. H. (2004). Shared decision making about screening and chemoprevention: A suggested approach from the U.S. Preventive Services Task Force. American Journal of Preventive Medicine, 26, 56-66. doi:10.1016/j.amepre.2003.09.011

Smith, S. D., Kimberling, W. J., Pennington, B. F., \& Lubs, H. A. (1983). Specific reading disability: Identification of an inherited form through linkage analyses. Science, 219, 1345-1347. doi:10.1126/science.6828864

Tan, T. W., Lim, S. J., Khan, A. M., \& Ranganathan, S. (2009). A proposed minimum skill set for university graduates to meet the informatics needs and challenges of the "-omics" era. BMC Genomics, 10(Suppl. 3), Proceeding S36. doi:10.1186/1471-2164-10-S3-S36

Walter, F. M., Emery, J., Braithwaite, D., \& Marteau, T. M. (2004). Lay understanding of familial risk of common chronic diseases: A systematic review and synthesis of qualitative research. Annals of Family Medicine, 2, 583594. doi:10.1370/afm.242

Yu, W., Gwinn, M., Clyne, M., Yesupriya, A., \& Khoury, M. J. (2008). A navigator for human genome epidemiology. Nature Genetics, 40, 124-125. doi:10.1038/ng0208-124

Zajtchuk, R. (1999). New technologies in medicine: Biotechnology and nanotechnology. Disease-A-Month, 45, 453-495.

Fecha de recepción: Agosto de 2010.

Fecha de aceptación: Marzo de 2011. 